\title{
A administração com foco no usuário-cidadão: realizações no governo federal brasileiro nos últimos 5 anos ${ }^{1}$
}

\author{
Marianne Nassuno
}

A Reforma do Aparelho do Estado empreendida pelo governo Fernando Henrique Cardoso foi iniciada com a edição de seu Plano Diretor, em novembro de 1995. Passados cinco anos, é possível fazer um balanço desse processo - uma vez que já existem informações e experiências acumuladas — no sentido de apresentar realizações e de identificar alguns avanços e desafios à direção adotada.

Neste texto, pretende-se revisar algumas ações implementadas no processo iniciado há cinco anos no governo federal brasileiro, analisando e classificando essas experiências de modo a propiciar conhecimento sistematizado sobre casos concretos de utilização do conceito da administração com foco no usuário e trazer informações sobre a direção em que a mudança vem ocorrendo.

Como a noção de foco no usuário-cidadão pode ter interpretações bastante diversas, ${ }^{2}$ neste texto, pretende-se mostrar como uma diretriz geral da reforma - voltar a prestação de serviços públicos para o atendimento do usuário-cidadão — foi traduzida em experiências concretas, comentar o avanço que isso representa, bem como apontar alguns desafios a serem considerados.

Experiências voltadas para o atendimento das demandas do usuáriocidadão de serviços públicos implementadas em diversos países estão fundamentadas em teorias e práticas desenvolvidas no contexto das transformações que redesenham o papel do Estado com a adoção de programas de qualidade, iniciativa cuja implantação ocorreu inicialmente no setor privado. A busca permanente pela qualidade tem uma relação direta com o direcionamento da produção para atender as expectativas dos consumidores. ${ }^{3}$

Marianne

Nassuno é mestre em administração pública pela EAESP/FGV e integrante da carreira de Especialista em Políticas Públicas e Gestão Governamental. Atualmente é responsável pela Pesquisa ENAP.

Contato: marianne.nassuno@ enap.gov.br 
A importância de orientar as ações da administração pública para os usuários dos serviços foi reforçada por teorias sobre o setor público (escolha pública e teoria do agente) que assumem que os indivíduos atuam para maximizar o próprio bem-estar. No caso dos burocratas públicos isso significa maximizar os seus interesses individuais por meio do aumento do orçamento que controlam e do seu poder discricionário, não atuando assim em função do interesse público (Myers e Lacey, 1996).

Adicionalmente, a importância da dimensão usuário-cidadão também foi enfatizada no Brasil com a discussão sobre as origens da crise do Estado, que aponta que essa crise refere-se, sobretudo, à "extenuação do Estado como fator de contenção de uma sociedade civil em processo de expansão e dotada de crescente densidade organizacional, razão pela qual o descompasso Estado-sociedade situa-se no cerne dos impasses presentes" (Diniz e Boschi, citado por Diniz, 1997: 21). Sendo assim, formas de gestão que aumentem o universo dos atores envolvidos podem trazer elementos novos para a definição de modalidades alternativas de intervenção pública. "Tais considerações colocam em evidência a necessidade de se definirem novas formas de gestão, mediante a criação de mecanismos e instrumentos que viabilizem a cooperação, a negociação e a busca de consenso" (Diniz, 1997: 36).

Nesse sentido, o processo cujas diretrizes estão contidas no Plano Diretor da Reforma do Aparelho do Estado situa-se entre as iniciativas da assim chamada 'segunda onda' de reformas. "Nos anos 80 , a preocupação fundamental da 'primeira onda' de reformas foi promover o ajuste estrutural das economias em crise, particularmente aquelas altamente endividadas e em desenvolvimento, como a do Brasil. Já nos anos 90, quando se percebe que este reajuste não poderia, em termos realistas, levar ao Estado mínimo, temos a 'segunda onda' de reformas. Enquanto na primeira onda o domínio da perspectiva leva, em relação ao Estado, essencialmente à política de dowsizing, a segunda onda de reformas tem caráter institucional. Agora, o projeto fundamental é reconstruir ou reformar um Estado, recuperando a sua governança" (Bresser Pereira, 2000: 17). Entende-se por governança a capacidade financeira e administrativa, em sentido amplo, de um governo implementar políticas, incluindo a sua capacidade de agregar os diversos interesses (Bresser Pereira, 1998).

No Plano Diretor (Brasil, 1995), a dimensão usuário-cidadão está colocada em termos da identificação do cidadão como cliente privilegiado dos serviços públicos e da previsão de mecanismos de controle social, com a participação de entidades da sociedade civil.

A abordagem do foco no usuário-cidadão foi adotada em iniciativas tanto no âmbito central, como orientação geral de algumas ações, quanto no âmbito descentralizado, envolvendo diversas instituições. $\mathrm{O}$ controle social foi implementado com a participação de entidades representativas 
da sociedade civil como membros do conselho de administração das Organizações Sociais.

Essas realizações representam a concretização de princípios gerais do Plano Diretor. Embora se tratem de intervenções pontuais, essas iniciativas serão analisadas - com base na literatura sobre o tema - no sentido de identificar indicações do modelo de gestão pública ora em desenvolvimento. Se, de um lado, elas mostram as possibilidades de realização da proposta inicial, em termos do conceito de cidadania a elas associado, da abertura de espaços no interior do Estado para a incorporação de outras perspectivas e da possibilidade de melhoria da prestação de serviços públicos; de outro, ilustram alguns desafios associados à perspectiva do foco no cliente, que não devem ser negligenciados. Em especial, destaca-se a questão da definição de quem são os usuários, as limitações das informações provenientes dos usuários e o risco de considerar apenas a perspectiva de alguns grupos de interesse organizados.

A apresentação das experiências concretas que traduziram a diretriz geral da reforma de voltar a prestação de serviços públicos para o atendimento do usuário-cidadão, bem como de alguns avanços e desafios a ela associados será realizada da seguinte forma. Será apresentado como os elementos cidadão e controle social são tratados no Plano Diretor, visando explicitar as diretrizes gerais colocadas na dimensão usuário-cidadão pelo documento inicial da reforma. Esses elementos dizem respeito à consideração do cidadão como cliente dos serviços públicos e à previsão da participação de entidades representativas da sociedade civil no conselho de administração das Organizações Sociais. São apresentadas algumas realizações ocorridas a partir de 1995 nessas duas áreas e, finalmente, são apresentados alguns desafios apontados pela literatura com relação à orientação do foco no usuário na atual Reforma do Aparelho do Estado, são destacados os avanços e feitos os comentários finais.

\section{Plano Diretor e a dimensão usuário-cidadão}

No Plano Diretor, a relação entre a administração pública e o usuário-cidadão está presente nas medidas que fazem menção às dimensões cidadania e participação. Sendo assim, essa relação aparece mais explicitamente na identificação do cidadão como cliente privilegiado dos serviços públicos - que envolve a noção de que o atendimento das demandas e expectativas da sociedade é uma forma de garantir a cidadania e ressalta a importância de aumentar a abrangência das políticas sociais e promover melhor qualidade para os serviços sociais - e na menção da participação e controle direto da administração pública pelos cidadãos como forma de defender a coisa pública nas sociedades democráticas modernas. 
Assim, de acordo com o Plano Diretor, a dimensão usuário-cidadão está contemplada na identificação do cidadão como cliente do governo e na questão do controle social, prevista no projeto das Organizações Sociais. Apresentamos, a seguir, trechos selecionados que mostram como os elementos cidadão e participação são tratados no texto do Plano Diretor. Referindo-se ao elemento cidadão/cidadania, temos:

"É preciso, agora, dar um salto adiante, no sentido de uma administração pública que chamaria de gerencial, baseada em conceitos atuais de administração e eficiência, voltada para o controle dos resultados e descentralizada para poder chegar ao cidadão, em uma sociedade democrática é quem dá legitimidade às instituições e que, portanto, se torna cliente privilegiado dos serviços prestados pelo Estado" (Brasil, 1995: 10).

"É importante ressaltar que a redefinição do papel do Estado é um tema de alcance universal nos anos 90. No Brasil, essa questão adquiriu importância decisiva, tendo em vista o peso da presença do Estado na economia nacional tornou-se, conseqüentemente, inadiável equacionar a questão da reforma ou da reconstrução do Estado, que já não consegue atender com eficiência a sobrecarga de demandas a ele dirigidas, sobretudo na área social. A reforma do Estado não é, assim, um tema abstrato, ao contrário, é algo cobrado pela cidadania, que vê frustradas suas demandas e expectativas" (Brasil, 1995: 14).

“[A] reforma do aparelho do Estado (...) está orientada para tornar a administração pública mais eficiente e mais voltada para a cidadania" (Brasil, 1995: 17).

"[P]retende-se reforçar a governança - a capacidade de governo do Estado - por meio da transição programada de um tipo de administração pública burocrática, rígida e ineficiente, voltada para si própria e para o controle interno, para uma administração pública gerencial, flexível e eficiente, voltada para o atendimento do cidadão" (Brasil, 1995: 19).

"O objetivo global da reforma do aparelho do Estado é "aumentar a governança do Estado, ou seja, sua capacidade administrativa de governar com efetividade e eficiência, voltando a ação dos serviços do Estado para o atendimento do cidadão" (Brasil, 1995:56).

Referindo-se à questão da participação/controle social, temos:

"Ainda no plano democrático, a prática cada vez mais freqüente da participação e controle direto da administração pública pelos 
cidadãos, principalmente, em nível local, é uma nova forma de defender a coisa pública” (Brasil, 1995: 20).

"Reformar o Estado significa melhorar não apenas a organização e o pessoal do Estado, mas também suas finanças e todo o seu sistema institucional-legal, de forma a permitir que o mesmo tenha uma relação harmoniosa e positiva com a sociedade civil" (Brasil, 1995: 56).

“O objetivo para os serviços não-exclusivos é lograr um controle social direto desses serviços por parte da sociedade por meio dos conselhos de administração das Organizações Sociais. Mais amplamente, fortalecer práticas de adoção de mecanismos que privilegiem a participação da sociedade tanto na formulação quanto na avaliação do desempenho das Organizações Sociais, viabilizando o controle social; aumentar a eficiência e qualidade dos serviços, atendendo melhor o cidadão-cliente a um custo menor" (Brasil, 1995: 59).

"[B]usca-se por meio das Organizações Sociais uma maior participação social, na medida em que elas são objeto de um controle direto da sociedade por meio de seus conselhos de administração recrutado no nível da comunidade à qual a organização serve" (Brasil, 1995: 74).

Os trechos selecionados do Plano Diretor mostram que, da mesma forma que experiências de outros países, as diretrizes relativas à dimensão usuário-cidadão envolvem tanto o desenvolvimento de formas novas de envolvimento dos cidadãos quanto a adequação dos serviços públicos às necessidades dos usuários. No Plano Diretor, o usuário-cidadão é considerado no seu papel como cliente privilegiado da prestação de serviços públicos, sendo capaz de fazer uma avaliação dos serviços prestados, ao passo que na sua participação como cidadão é enfatizada a contribuição fornecendo subsídios para a implementação de políticas públicas.

“[T]hese new forms of citizen participation (...) are in many ways perfectly consonant and consistent with emerging forms of public service delivery which aim at enhancing customer choice and strengthening the position of the citizen vis-à-vis the public sector. Thus, they could be seen as an attempt by government to develop new forms of citizen involvement in politics and policy making (that is, in policy input matters) at the same time as public services (policy output) are becoming less standardized and more customer attuned" (Pierre, 1998: 138). 
No levantamento de realizações da Reforma do Aparelho do Estado

no Brasil, objeto deste texto, será dada ênfase às práticas voltadas para a reorientação das ações para o usuário-cidadão dos serviços públicos e ao mecanismo de controle social previsto no projeto das Organizações Sociais, pois ele é explicitamente associado no texto do Plano Diretor ao tema da participação.

Serão apresentadas, a seguir, realizações do governo federal voltadas para a reorientação das ações na direção do usuário-cidadão dos serviços públicos e para a implementação do controle social previsto no projeto das Organizações Sociais.

\section{Ações voltadas para o usuário-cidadão dos serviços públicos}

A reorientação das ações do governo federal para o usuáriocidadão dos serviços públicos envolveu iniciativas tanto centralizadas, do órgão responsável pela condução da Reforma do Aparelho do Estado, ${ }^{4}$ quanto ações descentralizadas, implantadas em unidades de diversas instituições públicas.

Dentre as iniciativas adotadas pelo órgão responsável pela condução da Reforma do Aparelho do Estado podem ser destacadas:

- criação das Centrais de Atendimento, incorporadas posteriormente no Projeto Atendimento Integrado, visando incentivar a implantação de unidades integradas de atendimento, que reúnem, em um único local, representações de órgãos públicos federais, estaduais e municipais, funcionando de forma articulada e contando com servidores especialmente treinados para atender o público. Tais unidades encontram-se implantadas em diversos Estados da Federação, entre eles, Rio Grande do Sul, Santa Catarina, Paraná, São Paulo, Minas Gerais, Bahia, Ceará, Maranhão etc.

- realização da 1a Pesquisa Nacional de Satisfação do Usuário dos Serviços Públicos com o objetivo de aferir a percepção do cidadão brasileiro, usuário direto ou potencial, sobre a qualidade dos serviços públicos nos setores educação, saúde e previdência social, com base na experiência concreta de uso. Foram consideradas cinco dimensões da qualidade em serviço, que agregam os vários atributos envolvidos no processo de prestação de serviços: processo, prestabilidade, confiabilidade, empatia e aspectos tangíveis. ${ }^{5}$ Com a pesquisa, o governo federal pretende ter uma primeira referência da percepção do usuário sobre o serviço público que permitirá a construção de um indicador nacional médio de satisfação. O resultado da primeira pesquisa representa apenas um parâmetro; pretende-se promover e incentivar as melhorias necessárias a serem alcançadas de forma progressiva nos próximos anos. 
- Decreto do Sistema Nacional de Avaliação da Satisfação do Usuário dos Serviços Públicos (no 3.507, de 13 de junho de 2000), que dispõe sobre o estabelecimento de padrões de qualidade do atendimento prestado aos cidadãos pelos órgãos e entidades da administração pública federal. Esses padrões deverão ser observados na prestação de todo serviço ao usuário-cidadão, avaliados periodicamente e divulgados ao público. Os padrões de qualidade devem estar relacionados à atenção, respeito e cortesia no tratamento ao usuário, à definição de prioridades para o atendimento, tempo de espera para o atendimento e prazo para o cumprimento dos serviços, mecanismos de comunicação com os usuários, entre outros. Todos os órgãos e entidades públicas federais deverão divulgar os resultados da avaliação de seu desempenho em relação aos padrões de qualidade do atendimento fixados, pelo menos uma vez por ano.

A existência de um sistema nacional e permanente de avaliação, associado à vigência de padrões mínimos, visa estimular a construção de uma consciência crítica por parte dos usuários dos serviços públicos. Considera-se que essas ações combinadas contribuirão para aumentar progressivamente o nível de exigência por melhoria na qualidade dos serviços públicos (Brasil, s/d).

As ações voltadas para o usuário-cidadão no âmbito do órgão responsável pela condução da Reforma do Aparelho do Estado consideram o usuário como uma fonte de informações sobre os serviços públicos (1- Pesquisa Nacional), estão voltadas para o aperfeiçoamento do processo de prestação de informações e serviços públicos (Projeto Atendimento Integrado $)^{6} \mathrm{e}$ para o desenvolvimento de padrões obrigatórios para o atendimento ao usuário-cidadão (Sistema Nacional).

Essas ações fazem parte do Programa de Qualidade no Serviço Público ${ }^{7}$ que atua em três grandes eixos: atendimento ao cidadão, avaliação da satisfação do usuário e incentivo à melhoria da qualidade, os quais dizem respeito ao "aperfeiçoamento das formas de atendimento ao cidadão, orientando a implantação de mecanismos e instrumentos adequados e eficazes que promovam a qualidade no atendimento; a avaliação da satisfação do usuário com os serviços públicos, instrumentalizando as organizações a avaliarem seus resultados por meio da interação com o cidadão; e o incentivo à melhoria do atendimento, mobilizando e prestando assessoria técnica às organizações públicas" (Brasil, 2000).

As iniciativas implementadas no âmbito descentralizado, envolvendo diversas instituições do governo federal voltadas para o usuário-cidadão dos serviços públicos, consideradas neste trabalho, foram coletadas a partir de uma seleção das experiências premiadas no Concurso de Inovações na Gestão Pública Federal - Prêmio Helio Beltrão, organizado pela ENAP Escola Nacional de Administração Pública, Ministério do Planejamento, Orçamento e Gestão e o Instituto Helio Beltrão. ${ }^{8}$ 
Considera-se que o Concurso de Inovações na Gestão Pública

Federal - Prêmio Helio Beltrão constitui um meio propício para a coleta dessas experiências, uma vez que o foco no usuário tem sido utilizado como critério para a escolha das experiências vencedoras. A utilização do critério foco no usuário como requisito resultou na apresentação para o concurso de diferentes experiências apontando concretamente áreas, tipos de serviço, tecnologias utilizadas, formas de atendimento e evolução dos produtos e serviços públicos oferecidos ao usuário-cidadão. Essas experiências estão mais relacionadas com as dimensões de aperfeiçoamento do processo de prestação de serviços para o usuário-cidadão e para ampliação do acesso a informações e serviços públicos.

O conjunto de experiências premiadas com foco no usuário-cidadão em diversas edições do Concurso de Inovações na Gestão Pública Federal — Prêmio Helio Beltrão, oferece informações sobre como o conceito da administração, com foco no usuário, vem sendo traduzido na prática em experiências concretas de instituições públicas e permite conhecer os avanços e desafios do setor público federal para a melhoria do fornecimento de produtos, serviços e informações.

Rua (1999), em um texto que analisa as experiências premiadas nas duas primeiras edições do concurso, identifica que a dimensão relativa ao atendimento do usuário-cidadão foi a que apresentou a segunda maior ocorrência de inovações. Segundo a autora, esse fato permite uma avaliação positiva das mudanças recentes na administração pública:

"Primeiro, porque expressa uma sensibilização ao princípio central do modelo de administração gerencial — o foco no usuário-cidadão. Segundo, porque sugere o início de uma importante mudança comportamental, uma vez que sinaliza no sentido da ruptura do caráter auto-referido típico do modelo de administração burocrática. Terceiro, porque a maioria das inovações nessa dimensão apresenta custos relativamente baixos e resultados imediatos em termos da qualidade dos serviços (eficácia)" (Rua, 1999: 290).

As experiências premiadas no concurso mostram que o foco no usuário foi adotado por diversas instituições, destacando-se a Secretaria da Receita Federal do Ministério da Fazenda; e o Instituto Nacional do Seguro Social (INSS), vinculado ao Ministério da Previdência e Assistência Social (MPAS).

Os projetos da Secretaria da Receita Federal estão fortemente relacionados à utilização de tecnologia da informação e da Internet para fornecimento de informações e prestação de serviços — disponibilização de programas de Imposto de Renda na Internet e em disquete, prestação de atendimento via $e$-mail e emissão de certidão negativa de débitos de 
tributos via Internet - embora existam também experiências voltadas à

criação de centrais de atendimento ao contribuinte e à melhoria da rotina do atendimento.

No INSS destacam-se as iniciativas de atendimento itinerante em diversos Estados da Federação, verificando-se ainda projetos de Central de Atendimento e a utilização de tecnologia de comunicação (rádio).

No Banco do Nordeste vêm sendo realizadas iniciativas incluindo a criação da Central de Orientação ao Cliente, criação do serviço de agência itinerante para o atendimento de clientes em locais em que não há agências e o redesenho do processo de concessão de crédito com vistas a melhor atender ao cliente.

No Ministério do Trabalho e Emprego criou-se uma central de atendimento telefônica facilitando o acesso às informações e serviços prestados e implantou-se um serviço móvel para o atendimento em bairros periféricos e na zona rural em uma unidade descentralizada.

No Centro Tecnológico Aeroespacial foram adotados dois projetos voltados para a melhoria de rotinas de atendimento: marcação de consultas por telefone para eliminar as filas de espera e a criação de um manual do usuário.

A Empresa Brasileira de Correios e Telégrafos (ECT) apresentou duas experiências voltadas para melhorar o acesso dos cidadãos aos serviços: em um caso, para a solicitação de segunda via de documentos sem que tenham de se locomover ao local de emissão e em outro, para o recebimento de correspondência em áreas urbanas não organizadas com a instalação de caixas postais comunitárias.

Verificam-se também iniciativas isoladas implantadas por unidades específicas. Esse é o caso da Central de Atendimento ao Público da Superintendência do Instituto Brasileiro do Meio Ambiente e dos Recursos Renováveis (IBAMA), na Paraíba; da central de atendimento para simplificar e agilizar a criação e registro de empresas comerciais e civis do Departamento Nacional de Registro do Comércio; a melhoria do atendimento no ambulatório Maria da Glória; a divulgação de previsão do tempo pela Internet, realizada pelo Instituto Nacional de Pesquisas Espaciais (INPE); do Projeto Vida no Posto de Assistência Médica do Méier; dos Consulados Itinerantes do Ministério das Relações Exteriores, entre outras.

Essa breve descrição das experiências com foco no usuário implementadas permite algumas observações. Existem instituições nas quais o conceito do usuário-cidadão parece estar inserido em uma abordagem mais global. É o caso, sobretudo, da Secretaria da Receita Federal e do INSS. Existem outros casos em que o foco no usuáriocidadão pode ser base para experiências localizadas, aparentando não se inserir em uma estratégia maior. 
A disseminação do projeto Central de Atendimento entre as unidades da Receita Federal mostra como a estratégia global voltada para o usuário-cidadão está sendo implementada na instituição. Em um primeiro momento, a meta previa a implantação da iniciativa nas 82 Delegacias da Receita Federal. Nessas, 47 Centrais de Atendimento estavam em funcionamento pleno, 18 em funcionamento parcial e dez em estudos, faltando apenas sete para que fosse atingida a totalidade das Delegacias. Há também Centrais de Atendimento funcionando plenamente em três Inspetorias e duas Agências, de acordo com informações contidas no projeto apresentado pela Secretaria da Receita Federal em 1995.

As experiências premiadas do INSS mostram que a estratégia global está sendo desenvolvida para além da administração central, em unidades espalhadas no território nacional (Pará, Paraíba, Rondônia, Rio Grande do Sul e Pelotas). Nas unidades descentralizadas do INSS, foram criados postos itinerantes - que incluem a utilização de barcos e trailers — para orientar e regularizar a situação dos contribuintes, implantou-se um serviço móvel com voluntários em shoppings, feiras, exposições etc., para levar atendimento e informações aos usuários e foi desenvolvido um programa de ação, com objetivo de implantar um modelo de atendimento ao cliente, em conjunto com a Empresa de Processamento de Dados da Previdência Social (DATAPREV).

Esses projetos se enquadram em um programa mais amplo de melhoria do atendimento, que envolve ações como: ampliação das horas de atendimento, com atendimento ininterrupto; instalação de terminais de auto-atendimento; ampliação da rede de agências e unidades de atendimento; ampliação do serviço de teleatendimento; qualificação dos servidores para atendimento ao cliente. Foram definidos padrões de duração para diversas modalidades de atendimento, que em alguns casos estão sendo superados na prática, de acordo com o projeto da experiência apresentado pelo MPAS em 2000. ${ }^{9}$

É interessante notar que as duas instituições, em que se pode verificar o desenvolvimento de uma estratégia global de orientação para o usuário-cidadão, têm em suas atividades um componente econômico: tratam-se de duas instituições arrecadadoras de receitas públicas (Secretaria da Receita Federal e INSS). Entretanto, no que se refere ao INSS, as iniciativas analisadas mostram também um esforço de melhorar o serviço no sentido de ampliar o acesso aos recursos públicos garantindo a sua disponibilização àqueles que têm direito. Essas iniciativas merecem ser destacadas tendo em vista que grande parte dos usuários dos serviços da instituição pode ser classificada como cliente cativo, com possibilidades limitadas de escolha por prestadores de serviços alternativos. ${ }^{10}$

Com relação ao conteúdo das experiências, as iniciativas premiadas nas várias edições do Concurso de Inovações na Gestão Pública Federal 
— Prêmio Helio Beltrão, voltadas diretamente para prestação de serviços aos usuários-cidadãos, com qualidade e eficiência, podem ser agrupadas em quatro categorias: ${ }^{11}$

- as Centrais de Atendimento, que oferecem informações, integração de serviços em "guichê único", atendimento direcionado às necessidades dos usuários e, principalmente, atendimento conclusivo, ou seja, todo o processo - da demanda em relação ao produto ou serviço à obtenção do resultado — realiza-se em um único lugar e no menor tempo possível;

- o atendimento itinerante, que se refere à prestação de serviços e informações a segmentos de usuários, evitando o seu deslocamento para obtenção do serviço demandado. Inclui o atendimento dos usuários em suas próprias comunidades, bem como a viabilização de meios de acesso a serviços prestados em locais distantes. Nesse processo são prestados esclarecimentos e informações, atendimento às necessidades locais, bem como serviços;

- utilização de tecnologias de informação para prestação de informações/serviços ao usuário-cidadão (serviços informatizados online, Internet, serviços que usam o sistema de telefonia e outros meios de comunicação como o rádio);

- experiências voltadas para a revisão de processos tradicionais de atendimento aos usuários-cidadãos visando garantir maior agilidade e menor tempo de espera.

Cabe observar que a prestação de serviços públicos por meio de Centrais de Atendimento segue a tendência internacional do uso do one-stop model, ou seja, atendimento generalista em balcões ou quiosques promovendo o reagrupamento dos serviços públicos ou do fornecimento de informações. A implantação desse modelo de serviço está sendo incentivada pelo Projeto Atendimento Integrado desenvolvido pela Secretaria de Gestão, mencionado anteriormente.

Os projetos de atendimento itinerante e os processos de melhoria da prestação de serviços com o uso de tecnologias de informação, por sua vez, procuram equacionar o problema da viabilização do acesso aos cidadãos à prestação de serviços públicos.

No entanto, embora o objetivo dessas duas formas de implantar o foco no usuário seja o de aumentar o acesso a informações e serviços públicos, elas se diferenciam na medida em que o acesso garantido com a utilização de tecnologias de informação envolve experiências em que a prestação de serviços e a disponibilização de informações têm como pré-requisito o acesso prévio por parte do usuário aos suportes necessários à obtenção dos serviços: micro-computadores conectados à Internet, acesso a linhas telefônicas, fax etc. 
Já a prestação de serviços por meio de atendimento itinerante objetiva levar atendimento público - disponibilizando um determinado serviço ou conjunto de serviços — até os usuários-cidadãos que se encontram excluídos da prestação regular de serviços por morarem distantes dos centros fornecedores ou tendo dificuldade para se locomover até o local da prestação de serviços. Inclui iniciativas que levam a prestação do serviço ou informação até a comunidade ou evitam a necessidade de deslocamento para o acesso aos serviços. O serviço é levado aos usuárioscidadãos com os suportes tecnológicos (computadores, fax, Internet, arquivos, bancos de dados) necessários para viabilizar o atendimento. Esse tipo de experiência, além de prestar serviços voltados para as necessidades dos usuários, tem como foco a garantia do acesso aos serviços de maneira eqüitativa a todos os cidadãos demandantes, o que ressalta o seu caráter democratizante. ${ }^{12}$

Os projetos voltados para a melhoria dos processos tradicionais

de atendimento ao público incluem iniciativas voltadas para aperfeiçoar rotinas relacionadas ao atendimento: processo de triagem e encaminhamento do usuário-cidadão, gestão de filas, marcação de consultas por telefone, definição de parâmetros de atendimento etc. Essas experiências objetivam reduzir o tempo de espera e de atendimento, diminuir e/ou eliminar as filas. Os requisitos mínimos de atendimento ao público que devem ser estabelecidos pelas instituições públicas de que trata o decreto no 3.507 , de 2000, referem-se, sobretudo, a esse tipo de aperfeiçoamento de serviço.

Chama a atenção o fato de os Ministérios da Educação e da Saúde não estarem entre as instituições que se destacam em projetos premiados voltados para o usuário-cidadão, uma vez que nessas duas áreas, consideradas sociais por excelência, concentram-se atividades voltadas para a prestação de serviços públicos diretamente ao usuário-cidadão, especialmente aos de baixa renda.

Entretanto, diversas iniciativas que contribuem direta ou indiretamente para a qualidade do serviço prestado ao usuário-cidadão foram apresentadas por instituições que atuam nas áreas de educação e saúde e premiadas no concurso. ${ }^{13}$ No caso do Ministério da Educação ressaltam os exames nacionais do ensino básico e de cursos de nível superior, que representam uma forma alternativa de avaliar a qualidade da prestação do serviço, a partir dos seus resultados concretos e não diretamente considerando o grau de satisfação do usuário-cidadão.

Os resultados da 1a Pesquisa Nacional de Avaliação da Satisfação dos Usuários do Serviço Público mostram que nas áreas de educação, saúde e previdência encontram-se situações diversas no que se refere à satisfação dos usuários-cidadãos. Dentre os três serviços públicos pesquisados, o de educação pública de $1^{\circ}$ e $2^{\circ}$ graus foi considerado o mais satisfatório, 
com taxa de satisfação de 78,5\%, enquanto que o setor saúde foi considerado o menos satisfatório, com taxa de satisfação de $64,3 \% .^{14}$

É interessante notar que na área de educação a avaliação mais baixa $(64,4 \%)$ foi dada a uma característica 'segurança dentro da escola, evitando violência' que não está diretamente relacionada com a prestação do serviço de ensino. Já no setor saúde, as dimensões do serviço 'agilidade no atendimento' e 'garantia de acesso/processo de execução do serviço', ambas relacionadas de forma estreita ao atendimento ao usuário-cidadão, foram as que receberam as menores avaliações, não excedendo $61 \%$. Já nos serviços da Previdência Social, de competência exclusiva do MPAS e do INSS, a taxa de satisfação ficou em 72,5\%. No entanto, a dimensão ‘agilidade no atendimento' obteve a menor taxa de satisfação (64,1\%), a despeito das diversas iniciativas implementadas por essas instituições voltadas para a melhoria do atendimento, descritas anteriormente.

Finalmente, são dignas de menção as iniciativas da Secretaria da Receita Federal, embora essas se situem no grupo de ações que tem como requisito o acesso à tecnologia por parte do usuário-cidadão, apresentando, por essa razão, um componente de relativa exclusão. Para o equacionamento desta questão, o processo tem que ser complementado por iniciativas que induzam a participação dos grupos cujo acesso seria mais custoso, como, por exemplo, a construção de postos de serviço onde se ofereça amplo acesso à Internet. "O estabelecimento de lugares públicos, tais como quiosques, onde a população possa fazer consultas aos web sites governamentais pode ser uma forma de garantir o acesso universal à nova tecnologia" (Ferreira e Araújo, 2000). ${ }^{15}$

\section{Controle social nas Organizações Sociais}

O mecanismo de controle social previsto no Plano Diretor da Reforma do Aparelho do Estado refere-se à participação das entidades representativas da sociedade civil no conselho de administração de entidades prestadoras de serviços públicos não-exclusivos do Estado, qualificadas como Organizações Sociais.

As Organizações Sociais constituem uma forma institucional pensada para o setor de serviços que não pressupõem o poder do Estado, ${ }^{16}$ mas no qual a presença do Estado se justifica porque dizem respeito a direitos humanos fundamentais ou geram "economias externas", tais como as áreas de ensino, pesquisa científica e tecnológica, preservação do meio ambiente, cultura e saúde. A prestação dos serviços é descentralizada por meio de um processo denominado "publicização" para entidades de propriedade pública não-estatal ${ }^{17}$, denominadas Organizações Sociais. 
O instrumento de controle social previsto no projeto dessas organizações refere-se à participação de entidades representativas da sociedade civil no seu conselho de administração. ${ }^{18}$ No contexto de direcionar as ações da administração pública para o usuário-cidadão dos serviços públicos, esse instrumento de controle social pode ser entendido como uma forma de viabilizar o controle dos burocratas públicos pelos cidadãos, de forma a garantir eficiência na prestação de serviços. Utilizando a abordagem do principal-agente, Przeworski (1996) afirma que a ausência de controle dos burocratas gera ineficiência na implementação de políticas públicas sendo essa falta de controle resultado, entre outros, da inexistência de informações sobre o desempenho dos burocratas. ${ }^{19}$

"Mas os cidadãos, para os quais os serviços públicos são prestados, têm informações sobre o desempenho dos burocratas na implementação de políticas públicas que podem ser utilizadas pelos políticos (...). Com base nas informações dos usuários dos serviços públicos, os burocratas podem ser controlados pelos políticos" (Nassuno, 1999).

O conselho de administração das Organizações Sociais deverá ser composto por $20 \%$ a $40 \%$ de membros natos representantes do poder público; $20 \%$ a $30 \%$ de membros natos representantes de entidades da sociedade civil; até $10 \%$, no caso de associação civil, de membros eleitos dentre os membros ou associados; $10 \%$ a $30 \%$ de membros eleitos pelos demais integrantes do conselho, dentre pessoas de notória capacidade profissional e reconhecida idoneidade moral; e até $10 \%$ de membros indicados ou eleitos na forma estabelecida pelo estatuto.

O processo de implantação das Organizações Sociais foi iniciado com a edição da medida provisória n 1.591, de 26 de outubro de 1997, posteriormente convertida na lei no 9.637, de 15 de maio de 1998, estabelecendo o marco legal do projeto e dispondo sobre a qualificação de entidades como Organizações Sociais, a criação do Programa Nacional de Publicização, a extinção do Laboratório Nacional de Luz Síncroton e da Fundação Roquete Pinto e a absorção de suas atividades por Organizações Sociais.

Atualmente, três organizações estão funcionando no governo federal: a Associação Brasileira de Tecnologia de Luz Síncroton (ABTLuS); a Associação de Comunicação Educativa Roquette Pinto (ACERP) e a Bio-amazônia. Adicionalmente, existem ainda mais quatro instituições na área de Ciência e Tecnologia que querem se transformar em Organizações Sociais. A parte legal está sendo preparada com esse objetivo.

De acordo com a avaliação da Secretaria de Gestão, do Ministério do Planejamento, Orçamento e Gestão que passou a ser responsável pelo projeto, a partir de 1999, duas organizações funcionam bem: 
“(...) uma era um laboratório pequeno, bem organizado e administrado, cujo funcionamento foi potencializado ao ser transformado em instituição privada. Contrata sem concurso público e tem um sistema interno de avaliação, de compras, de auditoria e assim por diante. A outra é uma instituição criada para gerir um programa na Amazônia, a Bio-amazônia, que pesquisa material naquela região e é uma experiência nova" (Brasil, 2000: 36).

A ACERP enfrenta dificuldades que não têm a ver com o modelo e sim problemas administrativos existentes na instituição que lhe deu origem, a antiga TVE, Fundação Roquete Pinto. Por essa razão, a delegação de autonomia foi feita com muitas ressalvas (Brasil, 2000).

De acordo com seu estatuto, a ABTLuS tem por missão realizar pesquisa e desenvolvimento e formação de recursos humanos qualificados em Ciência e Tecnologia, em particular na área de aceleradores de partículas e suas técnicas de projeto e construção; projetar e construir fontes de luz síncrotron, seu instrumental científico e desenvolver suas aplicações em pesquisa básica e tecnológica, nos setores industrial e agro-industrial, no setor saúde e em áreas correlatas de tecnologia de ponta; desenvolver, gerar bens e/ou licenciar, para fabricação por terceiros, produtos e serviços de alta tecnologia; importar e/ou exportar materiais, componentes e equipamentos nas suas áreas de atuação, para o cumprimento de sua missão; colaborar com instituições de ensino, pesquisa e desenvolvimento nacionais e internacionais no cumprimento de sua missão; cooperar com a iniciativa privada em atividades de pesquisa e desenvolvimento; e incentivar a incubação e realizar a implantação de novas empresas de alta tecnologia.

A Bio-amazônia tem por objetivo colaborar com a implementação do Programa Brasileiro de Ecologia Molecular para o uso sustentável da biodiversidade da Amazônia (PROBEM/Amazônia), visando o desenvolvimento integrado da biotecnologia na Amazônia por meio da operação de uma rede nacional voltada para a bioprospecção e o apoio ao desenvolvimento de atividades industriais baseadas na região amazônica.

A ACERP tem por finalidade promover a educação, a cultura brasileira, o debate nacional, a formação profissional, por meio, inclusive, da operação dos canais de radiodifusão de sons e imagens, das tecnologias informacionais disponíveis, que permitam apoiar as políticas públicas. Pode prestar apoio cultural de instituições públicas e privadas a programas educativos de radiodifusão, bem como comercializar seus produtos e serviços.

Nas Organizações Sociais existentes, a participação das entidades representativas da sociedade civil está prevista no respectivo estatuto, conforme quadro a seguir: 
No que se refere à participação da sociedade, o Conselho de Administração da ABTLuS tem dois membros das entidades representativas dos interesses da comunidade científica (Academia Brasileira de Ciências e Sociedade Brasileira para o Progresso da Ciência) e um membro da entidade representativa dos interesses do setor industrial.

O controle social é exercido no Conselho de Administração da Bioamazônia por três membros representando interesses do empresariado, um de abrangência nacional, o outro de âmbito regional e outro ligado às micro e pequenas empresas; e dois membros de entidades representativas dos interesses da comunidade científica, um de âmbito nacional e outro de âmbito regional.

As entidades representativas da sociedade civil que participam do Conselho de Administração da ACERP são: uma entidade representativa dos interesses das empresas do setor de rádio e televisão e duas entidades que não representam interesses de setores ou grupos específicos, mas, mais propriamente, representam causas comuns (a literatura/cultura brasileira e a liberdade de imprensa).

Considerando-se a finalidade e a missão das Organizações Sociais existentes: formação de recursos humanos e realização de pesquisa básica e tecnológica nos setores industrial e agroindustrial, no setor saúde e em áreas correlatas de tecnologia de ponta (ABTLuS); o desenvolvimento integrado da biotecnologia na Amazônia e o apoio ao desenvolvimento de atividades industriais baseadas na região amazônica (Bio-amazônia), pode-se dizer que as atividades das Organizações Sociais criadas concentram-se na área de pesquisa científica e tecnológica, na qual o usuáriocidadão não é o público-alvo preferencial das ações, ao contrário das instituições da área de educação e saúde. Essas instituições não estão diretamente relacionadas a serviços a serem usufruídos pelo usuáriocidadão convencionalmente considerado.

No caso da ACERP, a justificativa para que o Estado promova atividades de rádio e televisão é justamente a de oferecer ao usuáriocidadão um produto - a educação, a cultura brasileira, o debate nacional, a formação profissional - diferenciado daquele oferecido pelo setor comercial de rádio e televisão, que, em princípio, oferece os bens culturais que o consumidor deseja. Sendo assim, as atuais entidades representativas da sociedade civil, membros do conselho de administração, que detém conhecimento e expertise específicos, podem contribuir mais efetivamente para a produção de bens culturais mais elaborados.

As peculiaridades das atividades desenvolvidas pelas Organizações Sociais existentes refletem-se nas entidades representativas de interesses da sociedade civil que participam dos respectivos conselhos de administração. São, de maneira geral, representantes da comunidade científica ou representantes do setor empresarial. São grupos cuja relação com a 
instituição não é apenas a de um mero usuário. Representam stakeholders com interesses mais abrangentes relacionados à missão e objetivos da organização e não apenas ao consumo de seus produtos. Pode-se dizer que as instituições que participam do conselho como entidades representativas da sociedade civil são aquelas que podem contribuir com informações técnicas e experiências qualificadas para que a organização realize os seus objetivos.

Essa visão é reforçada quando se consideram as competências que o conselho de administração dessas instituições exercem. Elas se referem basicamente a definir políticas, diretrizes, estratégias para as atividades, aprovar documentos de gestão (contrato de gestão, proposta orçamentária etc.) além de normas e regulamentos internos às organizações, para cuja consideração são necessários conhecimentos específicos.

\section{Avanços e desafios à direção adotada}

O direcionamento das ações da administração pública brasileira para o usuário-cidadão está presente no texto do Plano Diretor nos dispositivos que identificam o cidadão como o cliente dos serviços públicos e na previsão de um mecanismo de controle social - a participação de entidades representativas da sociedade civil no conselho de administração das Organizações Sociais.

As realizações da Reforma do Aparelho do Estado voltadas para a dimensão usuário-cidadão apresentadas neste texto e implementadas, tanto centralmente quanto no âmbito de instituições específicas, apontam para algumas direções. As ações com foco no usuário-cidadão visam:

- obter informações sobre os serviços públicos;

- o aperfeiçoamento do processo de prestação de serviços públicos;

- a melhoria da qualidade do serviço com a incorporação de requisitos relativos a atendimento ao usuário-cidadão;

- aumentar o acesso dos cidadãos a informações e serviços públicos, embora em alguns casos com um caráter relativamente excludente; e

- aperfeiçoamento do processo de definição de diretrizes e estratégias institucionais com a incorporação de atores com conhecimento e experiência específicos.

As iniciativas adotadas pelo órgão central do governo federal responsável pela condução da reforma são integrantes de um programa de qualidade, contribuindo para dar uma orientação única para ações com foco no usuário-cidadão implementadas descentralizadamente pelas instituições públicas. As experiências premiadas no Concurso de Inovações mostram que a difusão do conceito usuário-cidadão não ocorre de modo uniforme, havendo situações nas quais é incorporada como uma estratégia organizacional mais ampla, enquanto que em outras se verifica apenas 
a ocorrência de projetos isolados. Para que esses casos isolados se desenvolvam em estratégias institucionais mais amplas e globais, as ações adotadas em nível centralizado podem representar uma importante contribuição, na medida em que dão uma direção única a ser seguida pelas diversas instituições.

A literatura aponta alguns desafios à implementação da administração com foco no usuário-cidadão. Em primeiro lugar, no que se refere à utilização de informações dos usuários sobre os serviços públicos, menciona-se que a avaliação pode ser baseada em uma percepção que não necessariamente corresponde à realidade, associada ao contexto social no qual os serviços são prestados e experiências passadas.

"User evaluations are thus liable to a dual distortion, firstly from the impact of influences beyond those being evaluated, and secondly from the initial level of aspirations of the users who are part of the evaluation” (Knox e Mcalister, 1995: 419).

Usuários para os quais historicamente são oferecidos serviços de baixo nível, terão expectativas baixas a respeito dos serviços e ficarão satisfeitos com padrões que seriam inaceitáveis em outros contextos.

Em segundo lugar, outro item complexo apontado na literatura refere-se à definição de quem são os usuários dos serviços públicos específicos. É apontada a necessidade de se definir o usuário como uma entidade passível de ser pesquisada. $\mathrm{O}$ equacionamento desse problema inclui não apenas identificar aqueles que usam os serviços, mas também descobrir se esses usuários, como grupo, podem oferecer uma contribuição significativa para o serviço. A generalização pode ser problemática se os envolvidos representam um grupo muito restrito de indivíduos. A coesão do grupo pode ser assim uma consideração-chave na definição de uma amostra representativa da visão dos usuários dos serviços prestados.

No caso da prestação dos serviços públicos, o usuário mais óbvio é aquele que diretamente usufrui o serviço, mas além dele existem usuários potenciais e futuros com diferentes graus de interesse no serviço. ${ }^{23}$ A aceitação acrítica dos desejos dos usuários atuais pode ignorar os interesses de usuários futuros ou potenciais cujas decisões deverão ser influenciadas pelo serviço atualmente prestado. Segundo alguns autores, a utilização de informações sobre a satisfação dos usuários não deve substituir a discussão pública a respeito do desenvolvimento dos serviços públicos.

"While quality of service can be improved by taking account of the wishes of users, there is still need for a strategic vision of how each service should develop in the future. Without such a vision, stakeholders (including consumers) have no precise focus for discussion of their expectations of the service" (Younis et al, 1996: 380). 
Em terceiro lugar, considerando que as avaliações dos usuários devem não apenas ser utilizadas para monitorar o seu grau de satisfação, mas, sobretudo, para o aperfeiçoamento dos serviços públicos (Dinsdale e Marson, 1999), embora a 1ํㅡ Pesquisa Nacional represente uma experiência pioneira, precisa ser complementada por avaliações mais específicas das instituições e serviços envolvidos. Isso se aplica, em especial, aos serviços de educação e saúde que são prestados por diversas organizações públicas federais, estaduais e municipais e, sendo os resultados da pesquisa agregados, torna-se difícil apropriá-los para a melhoria das atividades das organizações individualmente.

Adicionalmente, segundo Gilbert et al (1998), indicadores de satisfação do usuário são adequados para a medir a eficácia institucional quando a agência governamental atende a usuários que têm liberdade de escolha entre diversos prestadores de serviços. Para instituições que atendem usuários cativos que não têm fornecedores alternativos a escolher - como é o caso das relacionadas a serviços previdenciários — devem ser incorporados indicadores alternativos, tais como a qualidade dos serviços prestados em termos de assegurar os direitos individuais. ${ }^{24}$

Em quarto lugar, existe a ressalva de que a administração com foco no usuário é uma estratégia que carrega princípios de mercado pouco adaptados ao setor público. Se para o setor privado, que valoriza o lucro, faz sentido criar diferenças entre os clientes, essas são inadimissíveis no setor público, em que a igualdade é um princípio essencial (Coutinho, 2000). Nesse sentido, os cidadãos sendo ou não usuários de serviços públicos específicos, são integrantes de uma comunidade e portadores de direitos e deveres. Ao contrário dos clientes do setor privado, freqüentemente não podem escolher um serviço alternativo, caso estejam insatisfeitos com o serviço prestado pelo setor público. As instituições públicas não atendem somente aos usuários diretos, mas preservam os direitos de todos os cidadãos, devendo equacionar os conflitos potenciais entre a satisfação dos usuários específicos e a proteção dos interesses de toda a comunidade ou cidadãos de um país (CCSN/CCMD, 1999).

A despeito desses desafios, é importante mencionar que a identificação do cidadão como usuário preferencial da administração pública representa um avanço em diversos aspectos. Em primeiro lugar, tem uma interface importante com a dimensão da relação entre o Estado e a sociedade, na medida em que se parte do conceito de cidadania como um conjunto de direitos, associando o desenvolvimento da cidadania a um processo de conquista e expansão dos direitos do cidadão, iniciado com a afirmação dos direitos civis e que inclui o usufruto dos serviços associados aos direitos sociais. Segundo Wanderley Reis (1990), o aspecto da provisão de serviços públicos não deve ser desconsiderado: 
"Temos de fazer clientes reais para que possamos esperar ter cidadãos em sentido pleno, capazes não só de expressar a autonomia que diz respeito especialmente aos direitos civis e políticos da cidadania, mas também de eventualmente exibir virtudes cívicas e exercer as responsabilidades que a concepção normativa da cidadania vê como o anverso daqueles direitos" (Wanderley Reis, 1990: 188).

A visão de que a melhoria da prestação de serviços públicos contribui para o fortalecimento da cidadania é confirmada por Rua (1999). Segundo a autora, a simplificação de procedimentos e a restruturação de processos de trabalho com vistas a melhorar o atendimento ao usuáriocidadão corrigem a situação na qual "a presença de irracionalidades nos procedimentos cria espaço para privilégios e relações de clientela e de favor", introduzindo assimetrias no tratamento ao cidadão:

"E, mesmo que não haja relações personalizadas de privilégio, procedimentos pesados aumentam os custos de oportunidade de forma diferenciada conforme os cidadãos, gerando desigualdades no acesso aos bens públicos e fragilizando o exercício da cidadania" (Rua, 1999: 290).

Em segundo lugar, cabe ressaltar que os projetos inovadores de atendimento itinerante, ao orientarem ações para o usuário-cidadão afastado dos centros prestadores de serviços, propiciam uma equalização do acesso, contribuindo para reduzir as diferenças no tratamento dos cidadãos e relativizando a crítica geral feita ao foco no usuário-cidadão de que contrariaria o princípio da igualdade que norteia as ações públicas.

Em terceiro lugar, a inclusão dos eixos atendimento ao cidadão e avaliação da satisfação do cidadão no Programa de Qualidade no Serviço Público pode contribuir para parametrizar as iniciativas com foco no cliente implementadas descentralizadamente nos programas de qualidades das várias instituições. Essa orientação única pode incentivar a concentração de esforços institucionais na adoção de iniciativas para o usuário-cidadão com as características das ações preconizadas centralmente, conferindolhes maior importância e abrangência.

Em quarto lugar, embora a utilização do foco no usuário-cidadão na administração pública seja recente e relativamente pouco desenvolvida, Myers e Lacey (1996: 346) avaliam que o conceito tem um potencial considerável para melhorar a qualidade dos serviços públicos e fortalecer instituições governamentais. Segundo os autores, um sistema efetivo de atendimento às queixas dos cidadãos pode aumentar a accountability do governo; serviços para os usuários podem vincular o público em geral aos esforços de reforma do setor público e dar uma conotação positiva ao processo que é geralmente associado a 
downsizing; se apoiado por maior transparência e uma separação clara da responsabilidade sobre a política e sobre a regulação, um arranjo bem desenhado de orientação para o cliente pode ajudar a enfraquecer as conexões entre o governo e grupos de interesse influentes e permitir aos governos responder de forma mais efetiva aos grupos mais vulneráveis da sociedade; informações sobre os usuários ao possibilitar o conhecimento em detalhe das necessidades de diferentes comunidades pode apoiar o desenho e implantação de mudanças.

Finalmente, é importante destacar também que alguns autores consideram a orientação para o usuário em programas de qualidade um requisito necessário para os governos no atual contexto de crescentes demandas e restrição de recursos. As ferramentas de qualidade não podem ser ignoradas pelo setor público tendo em vista o aumento das expectativas dos cidadãos no que diz respeito à amplitude e qualidade dos serviços. Younis et al apontam fatores que justificam a aplicação de estratégias voltadas para a melhoria da qualidade no setor público e as respectivas ferramentas como forma de melhorar a efetividade, a competitividade e a flexibilidade, uma vez que existem aspectos comuns de gestão entre o setor público e privado a despeito de o primeiro ter especificidades:

"[W]hatever the political philosophy, public sector services are no longer being taken for granted. Their purpose and operations are becoming subject to rigorous review by both politicians and consumers" (Younis et al, 1996: 373). ${ }^{25}$

No que se refere ao mecanismo de controle social das Organizações Sociais, percebe-se que nas instituições existentes foram escolhidas entidades representativas de interesses da sociedade civil que representam stakeholders com interesses mais amplos relacionados à missão e objetivos da instituição. Podem contribuir com conhecimentos, informações técnicas e experiências qualificadas para que a organização realize os seus objetivos. Tratam-se, na maioria das vezes de representantes de profissionais que atuam na área de competência da organização ou representantes do setor empresarial. $\mathrm{O}$ fato de as atividades dessas instituições não se referirem a serviços a serem usufruídos diretamente pelo usuário-cidadão convencionalmente considerado pode explicar a escolha desses membros no conselho de administração.

A definição de que as entidades devem participar do conselho de administração das Organizações Sociais é complexa. No entanto, o requisito de domínio profissional para a participação no conselho dessas organizações existentes pode reduzir a abrangência dessa participação. Embora, no caso das Organizações Sociais existentes, a especificidade das atividades realizadas por essas instituições justifique o requisito do 
conhecimento técnico para a escolha das entidades representativas da sociedade civil que participam do conselho de administração.

A ênfase na participação desses atores de elite na gestão das Organizações Sociais no sentido de fornecer conhecimento profissional e expertise coloca algumas questões. Como esses atores são aqueles potencialmente afetados pelas ações da instituição, existe o risco que usem sua influência no sentido de privilegiar os próprios interesses, reduzindo a possibilidade de formulação de uma política efetiva e apropriada:

“Also, non-governmental policy experts (...) will normally also make their assessment of the policy problem and whether indeed governmental action is the best way of resolving it" (Pierre, 1998: 149). ${ }^{26}$

Por outro lado, o dispositivo proposto no projeto das Organizações Sociais se inclui entre os mecanismos que os consumidores podem utilizar para chamar a atenção dos administradores sobre qualidade dos produtos e serviços sob a forma de voice, segundo a concepção de Hirschman (1970), pois inclui a possibilidade de envolver grupos de consumidores e a sua pressão sobre os prestadores de serviços de forma a assegurar a qualidade.

Além disso, a participação de entidades da sociedade civil em organizações prestadoras de serviços públicos, tal como previsto no projeto das Organizações Sociais pode ser, segundo Zifcak (2000), um instrumento para se promover deliberação administrativa. ${ }^{27}$ Esse autor procura definir algumas medidas que podem aumentar a deliberação administrativa entre o serviço público e os controladores independentes, entre elas, a previsão da participação de grupos de interesse e cidadãos nos conselhos administrativos de agências prestadoras de serviços público. Parte do conceito de democracia, no qual se enfatiza a necessidade do estabelecimento de certas pré-condições procedimentais para a efetiva deliberação democrática $^{28}$, e utiliza o conceito de contestability — a possibilidade de contestar permanentemente o poder - como requisito para a proteção da interferência arbitrária.

"As executive agencies and non-government organizations will have a direct relationship with and responsibility to their clientele, active consideration should be given to the establishment of consumer councils with whom agency officials should be required to consult regularly with respect to the nature, standard, quality and price of the service being delivered. Similarly, many such agencies and organizations will have their own boards of management. Membership of such boards might usefully be expanded to permit interested organizations, interest groups and citizens to play their part in board deliberation" (Zifcak, 2000: 271). 
De acordo com Zifcak (2000), a previsão da participação de entidades da sociedade civil no conselho administrativo das Organizações Sociais é um dos instrumentos que pode ampliar a deliberação administrativa propiciando a abertura de espaços no interior do Estado para a incorporação de outras perspectivas, cuja consideração se faz necessária para o equacionamento dos desafios colocados para a administração pública. ${ }^{29}$

\section{Comentários finais}

O texto tratou das iniciativas adotadas tanto em nível central quanto no âmbito de instituições específicas voltadas para o usuário-cidadão, considerando as diretrizes gerais estabelecidas no Plano Diretor: definição do cidadão como cliente dos serviços públicos e destaque da importância do controle social. As realizações mostram que as ações com foco no usuário-cidadão estão voltadas para a obtenção de informações sobre os serviços públicos; para o aperfeiçoamento do processo de prestação desses serviços; a melhoria da qualidade do serviço prestado incorporando requisitos relativos a atendimento ao usuário-cidadão; para o aumento do acesso dos cidadãos a informações e serviços públicos e incorporação de conhecimento e experiência no processo de definição de políticas e estratégias institucionais.

A adoção do foco no usuário-cidadão apresenta desafios relacionados à definição de quem são os usuários, o risco de a sua percepção sobre os serviços públicos ser enviesada e insuficiente para o desenvolvimento desses serviços, a necessidade de obter informações que possibilitem a melhoria dos serviços públicos e o fato de que o conceito de usuário pode embutir o princípio de diferenciação que é incompatível com o setor público.

Por outro lado, na medida em que considera a questão da qualidade e do aumento do acesso à prestação de serviços públicos, o foco no usuário pode fortalecer a dimensão da cidadania associada ao usufruto de serviços correspondentes aos direitos sociais. Os projetos de atendimento itinerante apresentados representam um exemplo de como essa estratégia pode levar a uma segmentação que não é necessariamente excludente. Adicionalmente, iniciativas voltadas para o usuário-cidadão podem aumentar a accountability do governo, ajudar a enfraquecer relações perversas entre o governo e grupos de interesse influentes, fornecer informações detalhadas sobre comunidades específicas e grupos mais vulneráveis da sociedade, além de contribuírem para equacionar as pressões crescentes dos cidadãos para a melhoria dos serviços públicos.

Além disso, a definição do cidadão como cliente dos serviços públicos pode ser associada a um conceito de cidadania e o mecanismo de controle social das Organizações Sociais representa a abertura de um espaço no interior do Estado para a incorporação de outras perspectivas 
para a deliberação administrativa, podendo constituir contribuições no sentido de aperfeiçoamento da interface entre Estado-sociedade.

No entanto, as ações iniciadas não são suficientes se retomarmos o diagnóstico da crise do Estado. O conceito de cidadania implícito na definição do cidadão como cliente da administração pública enfatiza a dimensão individual desse conceito, o do cidadão enquanto consumidor de bens e serviços. No entanto, o diagnóstico da crise do Estado aponta para a necessidade também de se fortalecer a cidadania nos seus aspectos coletivos. E, nesse sentido, as realizações precisam ser complementadas por outras ações voltadas para a constituição e o fortalecimento de outras instâncias de participação que contribuam para a consolidação de uma cidadania. Uma cidadania que implique o reconhecimento pelo indivíduo da legitimidade do Estado independentemente da provisão dos bens correspondentes aos direitos sociais, entendida como a integração a uma comunidade, que define a identidade do cidadão e a ele associa um conjunto de responsabilidades e deveres, e que dele exige um comportamento responsável. O projeto das Organizações Sociais apresenta avanços, no sentido da abertura de canais de comunicação com a sociedade no interior de instituições prestadoras de serviços públicos. No entanto, até pelo seu reduzido número e por características específicas das atividades realizadas pelas Organizações Sociais existentes, essa iniciativa precisa ser aprofundada tanto nas realizações quanto na compreensão dos diversos aspectos envolvidos.

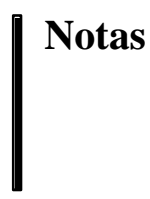

1 Este texto é uma versão revista e ampliada do paper apresentado no V Congresso do Centro Latino Americano da Administração para o Desenvolvimento (CLAD). A autora agradece a Regina Silvia Viotto Pacheco pelas sugestões e comentários.

2 Hood et al (1996) afirmam que embora o tema da orientação da administração pública para o cliente esteja em evidência nos processos atuais de reforma do setor público, não existe uma maneira única de realizá-lo. Considerando as dimensões 'grau de participação' (que varia de manipulação para controle dos cidadãos) e 'influência do cidadão’ (que varia de acesso a representação) identificam 16 diferentes tipos de ações orientadas para os usuários-cidadãos dos serviços públicos.

3 O referencial da qualidade dos serviços públicos foi incorporado pioneiramente pelo governo britânico desde a metade da década de 80 como resposta às críticas contra a ênfase na eficiência em detrimento da efetividade na prestação de serviços. Nas empresas privadas, a adoção da abordagem da administração da qualidade total foi resultado do aumento da concorrência e do nível de exigência dos consumidores. No setor público, "[a] introdução da perspectiva da qualidade surgiu quase no mesmo momento em que a administração pública voltava suas atenções aos clientes/consumidores” (Abrucio, 1997: 20). 
${ }^{4}$ O Ministério da Administração Federal e Reforma do Estado (MARE) até 1999 e o

Ministério do Planejamento, Orçamento e Gestão nos anos subseqüentes.

${ }^{5}$ Processo refere-se à percepção do usuário quanto à capacidade da organização em atender aos requisitos estabelecidos para os serviços, ou seja, cumprir com o que foi prometido; prestabilidade refere-se à percepção do usuário quanto à capacidade da organização em prestar bons serviços em tempo hábil; confiabilidade relaciona-se com fatores vinculados à imagem de credibilidade, competência e segurança da organização; empatia refere-se à percepção do usuário quanto ao cuidado e atenção individualizada que a organização disponibiliza; aspectos tangíveis referem-se aos aspectos visíveis dos serviços (Brasil, s/d).

6 Esse modo de prestação de serviços cumpre basicamente três funções: 1) melhorar o acesso aos serviços públicos em geral; 2) aumentar a comodidade na prestação de serviços em centros que oferecem, em um mesmo lugar, a totalidade ou grande parte dos serviços fornecidos por um determinado órgão público; e 3) ultrapassar os limites das competências (dos órgãos públicos) para fornecer serviços integrados, ou seja, possibilitar em um mesmo local a oferta de serviços públicos conexos.

7 Esse programa dá continuidade ao Programa de Qualidade e Participação iniciado em 1995. Nesse programa, a coordenação e implantação de programas de qualidade era feita descentralizadamente por cada órgão ou entidade e envolvia a elaboração de um plano de melhoria de gestão, com horizonte de um ano fundamentado no modelo de avaliação da gestão adotado pela Fundação para o Prêmio Nacional da Qualidade (Brasil, 1997).

8 O Concurso de Inovações na Gestão Pública Federal — Prêmio Helio Beltrão é promovido pela ENAP Escola Nacional de Administração Pública, Ministério do Planejamento, Orçamento e Gestão e uma organização não-governamental voltada para incentivar iniciativas no sentido de agilizar os serviços públicos, o Instituto Helio Beltrão. O concurso destina-se a identificar, divulgar e premiar experiências de inovação na gestão, já em curso na administração pública federal, com o objetivo de reconhecer e divulgar as iniciativas que estão dando certo na administração pública e promover a valorização de equipes de empreendedores, incentivando, desse modo, a participação de um número cada vez maior de servidores públicos na implementação de mudanças e inovações em seus setores e instituições. O concurso é realizado anualmente e, desde sua criação, em 1996, tem recebido ampla participação de órgãos e entidades da administração pública federal. Da primeira à quinta edição, (1996/2000), foram recebidos 526 projetos e premiadas 178 iniciativas.

9 Esse é o caso da modalidade de atendimento "orientação especializada" e "atendimento especializado com hora marcada" que tem como padrão de duração 15 minutos e 60 minutos respectivamente, sendo que estão sendo realizadas em 12 minutos e 41 minutos.

${ }^{10}$ Segundo Gilbert et al (1998), em instituições que atendem clientes cativos os usuários têm pouca influência relativamente a outros stakeholders e podem ser sujeitos a uma prestação de serviços em um nível mais baixo de satisfação.

${ }^{11}$ As experiências selecionadas segundo as quatro categorias encontram-se no Anexo. Trata-se de cinco experiências de implantação de centrais de atendimento, dez experiências de atendimento itinerante, oito experiências com a utilização de tecnologia de informação e seis projetos de melhoria de processos tradicionais de atendimento. Agradeço a Chélen Fischer de Lemos, da Pesquisa ENAP, pela seleção preliminar, classificação e comentários sobre as experiências.

${ }^{12}$ Nessas experiências ressalta-se o conceito de cidadania entendido como acesso aos serviços e o seu usufruto - referindo-se a um direito social conquistado, conforme será abordado nos comentários finais.

${ }^{13}$ Essas experiências foram apresentadas pelas seguintes instituições: Hospital de Clínicas de Porto Alegre, Universidade Federal Fluminense, Universidade Federal de Uberlândia, Ministério da Educação, Ministério da Saúde, Universidade Federal do Paraná, Centro Psiquiátrico Pedro II, Instituto Nacional do Câncer, Universidade Federal de Santa Maria, Fundo Nacional de Desenvolvimento da Educação, Centro Federal de Educação Tecnológica 
do Paraná, Fundação Nacional de Saúde, Universidade de Brasília, Escola Agrotécnica Federal de Cuiabá, Universidade Federal de Santa Catarina, Escola Técnica Federal de Campos, Universidade Federal de Goiás, Fundação Joaquim Nabuco, Escola Técnica Federal do Amazonas, Fundação Osvaldo Cruz, Fundação Universidade do Rio Grande, Delegacia do MEC no Paraná, Instituto Nacional de Estudos e Pesquisas Educacionais, HospitalEscola da Faculdade de Medicina do Triângulo Mineiro, Escola Agrotécnica Federal de Rio do Sul, Escola Técnica Federal do Ceará, Universidade Federal do Pará, Hospital Nossa Senhora da Conceição S.A., e Núcleo Estadual do Rio de Janeiro do Ministério da Saúde. Resumos dos projetos premiados estão divulgados na homepage da ENAP (www.enap.gov.br). Agradeço a Vera Lúcia Petrucci por mencionar esse aspecto.

${ }^{14}$ Cabe notar que, de acordo com a metodologia adotada na pesquisa, a nota de avaliação do serviço corresponde à taxa de satisfação do usuário em relação ao padrão que ele considera satisfatório. Isso significa que, na educação, faltam ainda $21,5 \%$ para que os serviços prestados atinjam o padrão considerado plenamente satisfatório, que em nenhum dos casos correspondeu à nota máxima dez.

${ }^{15}$ Os autores observam, no entanto, que nos países em que realizaram sua pesquisa, os governos centrais não têm investido na construção desses postos de serviço. Explicam a ausência de uma política nacional efetiva no sentido da universalização do acesso à Internet pelo fato de que nesses países o acesso popular às novas tecnologias já se encontra em estágio avançado, o que consideram não ser verdadeiro para países em desenvolvimento.

${ }^{16}$ Esse poder, denominado extroverso, é detido unicamente pelo Estado e refere-se ao "poder de constituir unilateralmente obrigações para terceiros, com extravasamento dos seus próprios limites" (Brasil, 1995: 51).

${ }^{17}$ Segundo o Plano Diretor, a propriedade pública não-estatal é uma terceira forma de propriedade, além das tradicionais pública e privada, constituída por organizações sem fins lucrativos, que não são propriedade de nenhum indivíduo ou grupo, estando diretamente orientadas para o atendimento do interesse público.

${ }^{18}$ Além do controle social possibilitado com a previsão de participação de entidades representativas da sociedade civil no conselho de administração das Organizações Sociais, estas serão sujeitas ao controle do governo, cujo principal instrumento será o Contrato de Gestão firmado pelo Ministro de Estado da área correspondente à atividade absorvida e pelo representante legal dessas organizações, após aprovação pelo conselho da entidade.

${ }^{19}$ Segundo o autor, em um sistema democrático, a prestação de serviços públicos é delegada pelos políticos eleitos aos burocratas, criando um problema de principal-agente, uma vez que as políticas implementadas pelos burocratas podem não ser aquelas definidas pelos políticos. Os burocratas têm razoável margem de manobra no desempenho de suas funções, pois é impossível regulamentar a sua ação em todas as circunstâncias, e podem ter objetivos próprios, diferentes dos interesses dos cidadãos e dos políticos que os representam.

${ }^{20}$ Demais membros do Conselho de Administração da ABTLuS: dois representantes do Ministério da Ciência e Tecnologia, indicados pelo Ministro, e dois representantes do Conselho Nacional de Desenvolvimento Científico e Tecnológico (CNPq), indicados pelo Presidente desse conselho, todos membros natos; um representante dentre os associados da ABTLuS; um empresário nacional, dois pesquisadores e dois membros ligados à área de política educacional, científica e/ou tecnológica, pessoas de notória capacidade profissional e reconhecida idoneidade moral, eleitos pelos integrantes do conselho; um funcionário de nível superior da associação, com mais de três anos de efetivo exercício no cargo, eleito pelos funcionários.

${ }^{21}$ Demais membros do Conselho de Administração da Bio-amazônia: sete membros representantes do poder público que serão: um representante da Secretaria de Coordenação da Amazônia (SCA/MMA), um representante do CNPq/MCT, um representante da 
Superintendência da Zona Franca de Manaus (SUFRAMA/MPO), um representante da Superintendência do Desenvolvimento da Amazônia (SUDAM-MPO), um representante do Governo do Estado do Amazonas, um representante do Banco do Brasil S/A e um representante do Banco da Amazônia S/A, todos membros natos; um membro eleito dentre os membros ou associados; cinco membros eleitos pelos demais integrantes do conselho, dentre pessoas de notória capacidade profissional técnico-científica ou empresarial e reconhecida idoneidade moral.

${ }^{22}$ Demais membros do Conselho de Administração da ACERP: seis representantes da Secretaria de Comunicação Social da Presidência da República, indicados pelo Secretário, todos membros natos; um representante eleito dentre os associados da ACERP; três pessoas de notória capacidade profissional e reconhecida idoneidade moral, eleitas pelos membros natos; um funcionário da associação eleito pelos funcionários.

${ }^{23}$ Pollitt (1990) problematiza a questão da definição dos usuários no caso dos serviços de saúde, elencando como usuários aqueles sob tratamento, aqueles que se sabe estão esperando por tratamento, aqueles que se acredita necessitarem de tratamento, mas que não estão procurando por ele ou aqueles que alguma vez vão precisar de tratamento e outros membros da comunidade afetados pela prestação de serviços, como os parentes dos pacientes.

${ }^{24}$ A satisfação de um prisioneiro no sistema carcerário pode não ser um indicador tão válido da eficácia geral de uma prisão. O que pode ser mais importante é se os prisioneiros estão detidos de forma efetiva com o devido respeito aos seus direitos (Gilbert et al, 1998).

${ }^{25}$ Entre os fatores estão também incluídos a crescente complexidade gerencial e estrutural do setor público que é equivalente ou superior à das grandes empresas; o aumento da possibilidade de comparar os estilos de gestão pública e privada à medida em que serviços são transferidos de um setor ao outro; a tentativa de melhoria da imagem do setor público com a utilização de práticas do setor privado; o fato de que os recursos financeiros são escassos.

${ }^{26}$ Com relação à participação de entidades representativas dos interesses dos usuários no conselho de administração das Organizações Sociais, Nassuno (1999), utilizando a abordagem do principal-agente argumenta que elas poderiam resolver o problema da ineficiência na relação entre os políticos e os burocratas, na medida em que os usuários dos serviços públicos detêm informações sobre o desempenho dos burocratas. No entanto, existem alguns desafios a serem considerados para a efetiva organização dos usuários para participação nesses conselhos, levando-se em conta as transformações descontínuas e fragmentadas ocorridas na estrutura e nos padrões de intermediação de interesses no Brasil. A análise a partir da abordagem da lógica da ação coletiva mostra que existem grupos com maiores incentivos para organizarem-se e se essa situação não for considerada, outros grupos que não os de representantes dos usuários podem participar da gestão e controle das Organizações Sociais e o mecanismo previsto poderá não contribuir para o aumento da eficiência na prestação dos serviços. As informações relativas ao desempenho dos burocratas poderão ser fornecidas por grupos representando interesses de fornecedores ou dos próprios funcionários (Nassuno, 1999).

${ }^{27} \mathrm{O}$ autor - em um texto em que analisa a reforma administrativa implementada na Austrália, processo, de um lado, que contribuiu para a constituição de um serviço público com mais consciência de custos, eficiente e efetivo, mas, de outro, teve efeitos negativos sobre a preservação e aprofundamento do diálogo democrático no Estado - considera que com as mudanças ocorridas no ambiente global da administração pública torna necessário repensar as estruturas administrativas, sistemas, procedimentos e valores sugerindo a incorporação de quatro valores para a reforma administrativa do próximo século: "contestability, accountability, procedural fairness e a commitment to public ethics" (Zifcak, 2000: 257). Em resposta a esse novo contexto o autor destaca que a discussão está convergindo para a necessidade de "revitalized democratic discussion, for a 
renaissance of public reason as one form of response to the challenges of global risk and global development. (...) If we are constantly to be surprised by the unintended consequences of scientific change and continuously challenged by the limits of the environment we inhabit, then (...) we need urgently to reinvigorate our democratic and deliberative capacities" (Zifcak, 2000: 258).

28 "The success of deliberative politics will rest upon the institutionalization of the procedures and conditions of effective communication" (Zifcak, 2000: 263).

${ }^{29}$ Deve-se observar, no entanto, que a efetiva operação desses espaços de deliberação envolve alguns cuidados. Quando consideram-se os diversos grupos envolvidos o consenso é difícil e uma gama ampla de perspectivas deve ser incorporada no processo. Esse cenário coloca a dificuldade de definir a importância relativa de cada perspectiva. Dadas as restrições de tempo, dinheiro, acesso aos interessados e metodológicas, devem ser feitas escolhas a respeito da perspectiva que será privilegiada no processo e o peso relativo dado aos diversos interessados se baseia na noção de justiça do tomador de decisão (House, citado por Knox e Mcalister, 1995). Adicionalmente, uma vez que, na definição dos usuários de um serviço público é preciso considerar se eles, como grupo, podem oferecer uma contribuição significativa para o serviço, alguns grupos de usuários podem se constituir em clientes preferenciais do setor público, um dos aspectos mais criticados da abordagem com foco no cliente (Abrucio, 1997). Por essa razão, os instrumentos que prevêem a colaboração de atores sociais na formulação de políticas públicas e na prestação de serviços públicos — como o mecanismo proposto por Zifcak (2000) — podem levar à consolidação de desigualdades políticas que são produto de desigualdades econômicas e sociais, sendo incapazes de gerar uma cooperação permanente (Cunill Grau, 1997).

\footnotetext{
Anexo
}

Experiências com foco no usuário-cidadão selecionadas no Concurso de Inovações na Gestão Pública Federal — Prêmio Helio Beltrão.

\section{A) Centrais de Atendimento}

\section{Central de Atendimento ao Contribuinte (CAC)}

Objetivo: atendimento integrado, eficiente e conclusivo aos contribuintes.

Ação: criação das CACs.

Ministério da Fazenda/Secretaria da Receita Federal 


\section{Central de Orientação ao Cliente}

Objetivo: centrar as ações com foco no cliente, assegurar autosustentabilidade e ampliar e aprimorar as relações sócio-políticoinstitucionais do banco.

Ação: implantação do Serviço de Orientação ao Cliente - cliente consulta um canal gratuito de comunicação entre o banco e a comunidade que oferece orientação sobre os ramos de negócio do banco.

Ministério da Fazenda/Banco do Nordeste

\section{Modelo de atendimento}

Objetivo: estabelecimento de um programa de ação com 31 projetos com o objetivo de melhorar o atendimento ao cliente.

Ação: implantação de um novo modelo de atendimento que compreende: realocação de pessoal, capacitação, atendimento preventivo e uma Central de Atendimento Técnico.

Ministério da Previdência e Assistência Social/INSS/DATAPREV/ Escritório Estadual do Pará

\section{Central de Atendimento ao Público}

Objetivo: melhoria na prestação dos serviços à população, com aumento da qualidade no atendimento e elevação do nível de satisfação dos usuários.

Ação: implantação de uma Central de Atendimento ao Público na Superintendência do IBAMA na Paraíba.

Inovação: integração dos serviços de arrecadação, cadastro e protocolo, aliado a um programa de educação ambiental por meio de vídeos ecológicos passados no local onde o serviço é prestado.

Ministério do Meio Ambiente e da Amazônia Legal/IBAMA/ Superintendência da Paraíba

\section{Central de Atendimento Empresarial — Sistema Fácil}

Objetivo: simplificar e agilizar a criação e registro de empresas comerciais e civis.

Ação: implementação da Central de Atendimento Empresarial

\section{- Sistema Fácil.}

Participação conjunta de várias instituições.

Desburocratização.

Ministério do Desenvolvimento, Indústria e Comércio Exterior/ Depto Nacional de Registro do Comércio - DNRC 


\section{B) Atendimento itinerante}

\section{INSS vai longe... na busca da comunidade}

Objetivo: informar, esclarecer, orientar e regularizar a situação do contribuinte junto à Previdência.

Ação: criação de Postos Itinerantes.

Parcerias com outras instituições (públicas e privadas).

Ministério da Previdência e Assistência Social/INSS/Superintendência Estadual de Rondônia

\section{Posto flutuante do Pará}

Objetivo: atender à população que tem dificuldade de se deslocar até os postos do INSS.

Ação: criação de posto flutuante com técnicos e peritos.

Ministério da Previdência e Assistência Social/INSS/Superintendência Estadual do Pará

\section{Consulados Itinerantes}

Objetivo: prestação de serviços consulares a brasileiros residentes em outras localidades e cidades nas quais não têm representação consular.

Ação: ida de servidores de consulados a localidades, dentro de suas áreas de jurisdição, onde exista um número significativo de brasileiros residentes, para prestar o serviço.

Ministério das Relações Exteriores

\section{Por terra, pelo ar, pelos rios, a}

\section{Previdência chega até você!}

Objetivo: levar atendimento, informação e esclarecimento aos usuários.

Ação: implantação de um serviço móvel com servidores voluntários que atuam em feiras, exposições, shoppings e áreas rurais.

Parcerias com outros órgãos e instituições.

Ministério da Previdência e Assistência Social/INSS/Superintendência Estadual do Rio Grande do Sul

\section{Programa agência itinerante}

Objetivo: atendimento in loco das necessidades dos clientes-alvo, orientação e operacionalização de negócios já demandados.

Ação: criação de um serviço de agência itinerante para atendimento in loco dos clientes em localidades onde não há agência. 


\section{Unidade móvel}

Objetivo: atender a população que tem dificuldade de acesso aos postos do INSS nas imediações de Pelotas.

Ação: criação de um posto móvel instalado em um trailer reboque, equipado com computador de bordo, modem com linha discada em conexão com o Posto de Benefícios de Pelotas/RS. Com esse sistema é possível obter acesso aos dados informatizados sobre manutenção e concessão de benefícios.

Parceria com outras instituições.

Ministério da Previdência e Assistência Social/INSS/Gerência Regional do Seguro Social de Pelotas

\section{Unidade móvel de atendimento}

Objetivo: atender a população (empregado ou empregador) localizada distante de uma unidade de serviço do MTE.

Ação: implantação de um serviço móvel para atender principalmente aos bairros periféricos e zona rural. Nos postos são emitidas carteiras de trabalho, requisições de seguro-desemprego, denúncias trabalhistas etc.

Parcerias com municípios, sindicatos etc.

Ministério do Trabalho e Emprego/Delegacia Regional da Bahia

\section{Recebimento de solicitações de 2 a via de documentos}

Objetivo: facilitar a obtenção de 2ㄹ via de documentos emitidos por cartórios para a grande população de outras regiões do país residentes em São Paulo, evitando deslocamentos às suas localidades de origem, com redução de custos e tempo para os interessados.

Ação: disponibilização da rede de agências da ECT em São Paulo - Capital e Região Metropolitana - para solicitações de 2 via de documentos como registros de nascimento, certidões de casamento, de óbito e de registro de imóveis, bem como certidões negativas de protesto. A captação é realizada mediante o recebimento de formulários preenchidos pelos interessados, que são distribuídos pelas agências e pagamento da taxa correspondente.

Ministério das Comunicações/ECT/Diretoria Regional de São Paulo Metropolitana

\section{Projeto Movimentação}

Objetivo: levar atendimento previdenciário à população amazonense que, por dificuldade de acesso, quase nunca se desloca à sede do Município ou à capital do Estado. 
Ação: projeto de interiorização da Previdência Social que não se limita à orientação mas, efetivamente concede, 'in loco', o benefício ao requerente graças às parcerias firmadas com órgãos oficiais instalados nos municípios e, também à estação de comunicação via satélite, que supre o precário atendimento de energia elétrica, comunicação de dados e voz da região.

Ministério da Previdência e Assistência Social/INSS/Gerência Executiva Amazonas

\section{Caixas postais comunitárias}

Objetivo: viabilizar a entrega de objetos de correspondência, com agilidade e segurança, aos habitantes das periferias e áreas de invasão.

Ação: instalação de um módulo de caixa postal em local definido pela população,geralmente uma escola, posto de saúde ou sede da associação de moradores, cuja gestão é compartilhada com a comunidade.

Ministério das Comunicações/ECT/Diretoria Regional do Paraná

\section{C) Tecnologias de informação}

\section{A Receita Federal na Internet}

Objetivo: melhorar o atendimento ao contribuinte.

Ação: inserção no site do Ministério da Fazenda da homepage do Imposto de Renda, com disponibilização dos programas de Imposto de Renda Pessoa Física e Jurídica e informações sobre o preenchimento das declarações; disponibilização da entrega da declaração via Internet.

Ministério da Fazenda/Secretaria da Receita Federal

\section{Declarações de renda de pessoa jurídica em disquete}

Objetivo: auxiliar e simplificar a tarefa do contribuinte.

Ação: fornecimento do programa gerador de declaração do Imposto de Renda pessoa jurídica nos órgãos da Receita Federal ou via Internet.

Ministério da Fazenda/Secretaria da Receita Federal

\section{Previsões de tempo através da Internet}

Objetivo: democratizar a informação de previsão meteorológica de tempo e criar um esquema mais eficiente de comunicação entre o usuário final e o Centro de Previsão de Tempo e Estudos Climático (CPTEC).

Ação: implementação de um programa simplificado de acesso, via Internet, às ações do CPTEC.

Ministério da Ciência e Tecnologia/Instituto Nacional de Pesquisas Espaciais. 


\section{Central de Atendimento "Alô Trabalho"}

Objetivo: apoiar, melhorar, agilizar e ampliar a capacidade de atendimento aos trabalhadores, empregados, entidades de representação, órgãos de classe e entidades públicas em âmbito nacional.

Ação: criação de uma central de atendimento denominada "Alô Trabalho" - linha telefônica com ligação gratuita, facilitando e simplificando o acesso às informações e serviços prestados pelo Ministério do Trabalho e Emprego e suas unidades descentralizadas.

Ministério do Trabalho e Emprego

\section{Atendimento de contribuintes por correio eletrônico}

Objetivo: garantir o acesso do contribuinte às informações.

Ação: criação do atendimento via e-mail, o qual possibilita a democratização, a agilidade e a qualidade da informação. A consulta via e-mail é respondida no prazo máximo de sete dias úteis.

Ministério da Fazenda/Secretaria da Receita Federal.

\section{Emissão de certidão negativa de débitos de tributos e contribuições federais, via Internet}

Objetivo: facilitar o acesso dos contribuintes aos documentos; desburocratizar a obtenção dos documentos; agilizar o processo de fiscalização e controle etc.

Ação: utilização de tecnologia web para implantar um sistema interativo da Secretaria da Receita Federal com o contribuinte via Internet.

Ministério da Fazenda/Secretaria da Receita Federal

\section{Rádio é prevenção}

Objetivo: divulgar orientações sobre saúde para população de locais mais afastados e de difícil acesso na Amazônia.

Ação: implementação de programa de rádio que divulga orientações sobre saúde, em que também são respondidas cartas de ouvintes sobre doenças específicas.

Presidência da República/Secretaria de Comunicação/Radiobrás e Fundação Nacional de Saúde

\section{Ação Comunicação}

Objetivo: divulgar informações e orientações sobre temas relativos à Previdência Social à população da Amazônia que vive em locais distantes e de difícil acesso à informação. 
Ação: implementação do jornal da Previdência Social, veiculado pela Rádio Nacional da Amazônia que informa, esclarece dúvidas e propõe soluções aos problemas dos ouvintes relacionados à Previdência Social.

Ministério da Previdência e Assistência Social/INSS

\section{D) Melhoria dos processos tradicionais de atendimento}

\section{Fim das filas}

Objetivo: acabar com as filas no ambulatório.

Ação: agendamento das consultas por telefone.

Ministério da Aeronáutica/Centro Técnico Aeroespacial

\section{Melhoria do atendimento no ambulatório Maria da Glória}

Objetivo: melhoria do atendimento e do ambiente físico do ambulatório.

Ação: treinamento de pessoal para atendimento ao público; melhoramento do espaço físico do ambulatório.

Ministério da Educação e do Desporto/Faculdade de Medicina do Triângulo Mineiro.

\section{Projeto Vida}

Objetivo: humanizar e dinamizar o atendimento no serviço de urgência do Posto de Assistência Médica do Méier/RJ.

Ação: restruturação do processo com identificação de casos prioritários, e encaminhamento de pacientes com integração de todos os setores da instituição.

Ministério da Saúde/Posto de Assistência Médica do Méier

\section{Sistema Nacional de Apoio ao \\ Gerenciamento do Atendimento - SAGA}

Objetivo: melhoria do atendimento nas unidades da Receita Federal

Ação: sistema eletrônico de coleta de dados de triagem e gerenciamento do atendimento da Receita Federal, em todas as suas etapas que torna possível aos chefes das unidades de atendimento ajustar as disponibilidades de material e recursos humanos às demandas quantitativas e qualitativas dos contribuintes, de modo a diminuir o tempo de espera e de atendimento e obter um alto grau de conclusividade.

Ministério da Fazenda/Secretaria da Receita Federal 


\section{Redesenho do processo de concessão de crédito}

Objetivo: busca da satisfação do cliente, por meio de processos mais ágeis, dinâmicos, descentralizados e desburocratizados.

Ação: reformulação do processos de concessão de crédito para atender melhor ao cliente.

Ministério da Fazenda/Banco do Nordeste

\section{Manual do usuário}

Objetivo: oferecer ao usuário parâmetros concretos e precisos para solicitar, obter e avaliar o atendimento de suas demandas.

Ação: elaboração de um manual do usuário contendo, para cada necessidade básica, informações sobre a finalidade do atendimento, os prérequisitos para o atendimento, a documentação necessária, o custo e o tempo.

Ministério da Aeronáutica/Centro Tecnológico Aeroespacial

\section{Referências bibliográficas}

Abrucio, F. (1997), O impacto do modelo gerencial na administração pública. Breve estudo sobre a experiência internacional recente. (Mimeo)

Brasil, Ministério do Planejamento, Orçamento e Gestão (2000), Gestão Pública Empreendedora. Brasília: Secretaria de Gestão do Ministério do Planejamento, Orçamento e Gestão. . (2000), Diretrizes para a Gestão de um Novo Brasil. Brasília: Secretaria de Gestão do Ministério do Planejamento, Orçamento e Gestão. . (s/d), 1ă Pesquisa Nacional de Satisfação dos Usuários dos Serviços Públicos, mimeo.

Brasil, Ministério da Administração Federal e Reforma do Estado (1997), "Organizações Sociais". Cadernos MARE da Reforma do Estado, Brasília, v. 2. (1997), "Programa de Qualidade e Participação na Administração Pública". Cadernos MARE da Reforma do Estado, Brasília, v. 4.

Brasil, Câmara da Reforma do Estado (1995), Plano Diretor do Aparelho de Reforma de Estado. Brasília.

Bresser Pereira, L.C. (1998), Reforma do Estado para a Cidadania: A Reforma Gerencial Brasileira na Perspectiva Internacional. Brasília: ENAP; São Paulo: Editora 34. . (2000), "Brasil — A reforma gerencial do Estado de 1995". Revista de Administração Pública, 34 (4), jul/ago.

CCSN/CCMD (1999), "Citizen-Centred Service: Responding to Needs of Canadians". Citizen-Centred Service Network. Ottawa: Canadian Centre for Management Development. 
Coutinho, M. J. V. (2000), “Administração pública voltada para o cidadão: quadro teóricoconceitual". Revista do Serviço Público, Brasília, ano 51, n. 3, jul-set.

Cunill Grau, N. (1997), Nuevas Formas de Gestión Pública y Representación Social. Centro Latinoamericano de Administración para el Desarollo. Caracas: Nueva Sociedad. (1991): Participación Ciudadana. Caracas: CLAD.

Dinız, E. (1997), Governabilidade, democracia e reforma do Estado: os desafios da construção de uma nova ordem no Brasil dos anos 90" in Diniz, E., Azevedo, S. de (orgs.), Reforma do Estado e Democracia no Brasil. Brasília: Editora Universidade de Brasília.

Dinsdale, G., Marson, D. B. (1999), "Citizen/Client Surveys: Dispelling Myths and Redrawing Maps". Citizen-Centred Service Network. Ottawa: Canadian Centre for Management Development.

Ferreira, S. G., Araúuo, E. A. (2000), "Modernização da gestão: E-governo o que ensina a experiência internacional". Informe-se BNDES. Rio de Janeiro: Secretaria de Assuntos Fiscais, n. 17, ago.

Ferreira, M.E., Umbelino, L.M. (orgs.). (1998), Ações premiadas no 2- Concurso de Experiências Inovadoras de Gestão na Administração Pública Federal. Brasília: ENAP.

Gilbert, G. R., Nichols, J. A., Roslow, S. (1998), "Measuring public sector customer service satisfaction". The Public Manager, winter.

Hirschmann, A. O. (1970), Exit, Voice and Loyalty. Cambrige: Harvard University Press.

InGRAHAM, P. W. (1998), "Making public policy - the changing role of the higher civil service", in Peters, B.G., Savoie, D. J. (eds.), Taking Stock. Assessing Public Sector Reforms. Canadian Centre for Management Development series on governance and public management. Montreal: McGill-Queen's University Press.

Hood, C., Peters, G., Wollmann, H. (1996), "Sixteen ways to consumerize public services: pick'n mix or painful trade-offs?" Public Money and Management.

Knox, C., Mcalister, D. (1995), "Policy evaluation: incorporating user's views" Public Administration, Blackwell Publishers Ltd. v. 73.

Lemos, C. F. de (2000), Ações premiadas no 5o Concurso de Experiências Inovadoras na Administração Pública Federal (no prelo).

Myers, R., LACEY, R. (1996), "Consumer satisfaction, performance and accountability in the public sector". International Review of Administrative Sciences, v. 62, n. 3, sep.

Nassuno, M. (2000), Reforma empreendedora da administração pública (mimeo). . (1999), "O controle social nas organizações sociais no Brasil", in

Bresser Pereira, L.C., Cunill Grau, N. (orgs.), O Público não-estatal na Reforma do Estado. CLAD. Rio de Janeiro: Editora Fundação Getúlio Vargas.

Paquin, M. (1998), "Innovation in public sector management", in Peters, B.G., Savoie, D. J. (eds.), Taking Stock. Assessing Public Sector Reforms. Canadian Centre for Management Development series on governance and public management. Montreal: McGill-Queen's University Press.

Petrucci, V.L., Rua, M. das Graças (orgs.). (1997), Ações premiadas no 1º Concurso de Experiências Inovadoras na Administração Pública Federal. Brasília: ENAP.

Petrucci, V.L., Umbelino, L.M. (orgs.). (2000), Ações premiadas no 4 Concurso de Inovações na Gestão Pública Federal - Prêmio Helio Beltrão 1999. Brasília: ENAP. (orgs.), (1999), Ações premiadas no 4o Concurso de Inovações na Gestão Pública Federal - Prêmio Helio Beltrão 1998. Brasília: ENAP.

PierRe, J. (1998), "Public consultation and citizen participation: dilemmas of policy advice", in Peters, B.G., Savoie, D. J. (eds.), Taking Stock. Assessing Public Sector Reforms. Canadian Centre for Management Development series on governance and public management. Montreal: McGill-Queen's University Press.

Pollitt, C. (1990), Managerialism and the Public Services. The Anglo-American Experience. Basil Blackwell, Inc. Cambridge. 
Przeworski, A. (1996), "On the design of the State: a principal-agent perspective". Paper apresentado no Seminário A Reforma do Estado na América Latina e no Caribe: Rumo a uma Administração Pública Gerencial. Brasília.

RuA, M. das Graças (1999), "Administração pública gerencial e ambiente de inovação: o que há de novo na administração pública federal brasileira", in Petrucci, V. L., Schwarz, L. (orgs.), Administração Pública Gerencial: a reforma de 1995. Ensaios sobre a reforma administrativa brasileira no limiar do século XXI. Brasília: Editora da Universidade de Brasília, ENAP.

Wanderley Reis, F. (1990), Gidadania democrática, corporativismo e política social no Brasil. Para a Década de 90 - Prioridades e perspectivas de políticas públicas. Brasília: IPEA.

Younis, T., Bailey, S.J., Davidson, C. (1996), “The application of total quality management to the public sector". International Review of Administrative Sciences, v. 62, n.3, sep.

Z IFCAK, S. (2000), "From Managerial Reform to Democratic Reformation: Towards a Deliberative Public Administration". International Public Management Journal, 2 (2A).

Legislação consultada:

Lei n. 9.637, de 15 de maio de 1998

Decreto Presidencial de 18 de março de 1999

Decreto n. 3.507, de 13 de junho de 2000

Estatuto da Associação de Comunicação Educativa Roquette Pinto (ACERP)

Estatuto da Associação Brasileira de Tecnologia de Luz Síncroton (ABTLuS)

Estatuto da Associação Brasileira para o Uso Sustentável da Biodiversidade da Amazônia (Bio-amazônia). 


\section{A administração com foco no usuário-cidadão: realizações no governo federal brasileiro nos últimos 5 anos \\ Marianne Nassuno}

O texto apresenta algumas realizações — voltadas para a implantação do foco no usuário-cidadão da reforma do aparelho do Estado - empreendida pelo governo federal brasileiro a partir de 1995. O foco foi colocado em termos da identificação do usuáriocidadão como principal cliente dos serviços públicos e da previsão de mecanismos de controle social. As realizações mostram, de um lado, as possibilidades de concretização da proposta inicial. Por outro ilustram alguns desafios associados à perspectiva do foco no cliente, que não devem ser negligenciados.

\section{La administración orientada hacia los usuarios-ciudadanos: acciones del gobierno brasileño en los últimos cinco años}

\section{Marianne Nassuno}

El artículo presenta algunas de las realizaciones de la reforma gerencial del gobierno brasileño - empesada a partir de 1995 — sobre todo las acciones para adopción de los principios de la administración orientada hacia los usuarios-ciudadanos. Tece comentarios acerca de la concepción del usuario-ciudadano como un cliente y los nuevos instrumentos creados com miras al estabelecimiento del controle social de los servicios públicos. Finalmente aborda los avanzos y desafios de la reforma para garantizar los medios necesarios para la adopción de la concepción del usuario-ciudadano como el cliente de los servicios públicos.

\section{Citizen-centered administration: achievements in the brazilian federal government of the last five years \\ Marianne Nassuno}

The article presents some of the achievements of the present managerial reform led by the federal government from Brazil. In special highlights the measures taken in order to implement the principles of the citizen-centered administration. The main advancements of the reform process are commented, as well as, the challenges to the client-focused actions which still have to be faced.

Ano 51

Número 4

Out-Dez, 2000

Marianne

Nassuno é mestre em administração pública pela EAESP/FGV e integrante da carreira de Especialista em Políticas Públicas e Gestão Governamental. Atualmente é responsável pela Pesquisa ENAP.

Contato: marianne.nassuno@ enap.gov.br 